\title{
Autoactive Alleles of the Flax L6 Rust Resistance Gene Induce Non-Race-Specific Rust Resistance Associated with the Hypersensitive Response
}

\author{
Paul Howles, Greg Lawrence, Jean Finnegan, Helen McFadden, Michael Ayliffe, Peter Dodds, and \\ Jeff Ellis
}

CSIRO, Plant Industry, GPO Box 1600, Canberra ACT 2601, Australia

Submitted 15 November 2004. Accepted 25 January 2005.

\begin{abstract}
L6 is a nucleotide binding site-leucine rich repeat (NBSLRR) gene that confers race-specific resistance in flax (Linum usitatissimum) to strains of flax rust (Melampsora lini) that carry avirulence alleles of the AvrL567 gene but not to rust strains that carry only the virulence allele. Several mutant and recombinant forms of $L 6$ were made that altered either the methionine-histidine-aspartate (MHD) motif conserved in the NBS domain of resistance proteins or exchanged the short domain C-terminal to the LRR region that is highly variable among $L$ allele products. In transgenic flax some of these alleles are autoactive; they cause a gene dosage-dependent dwarf phenotype and constitutive expression of genes that are markers for the plant defense response. Their effects and penetrance ranged from extreme to mild in their degree of plant stunting, survival, and reproduction. Dwarf plants were also resistant to flax rust strains virulent to wild-type $L 6$ plants, and this nonspecific resistance was associated with a hypersensitive response $(H R)$ at the site of rust infection. The strongest autoactive allele, expressed in Arabidopsis from an ethanolinducible promoter, gave rise to plant death dependent on the enhanced disease susceptibility 1 (EDS1) gene, which indicates that the mutant flax (Linaceae) L6 gene can signal cell death through a defined disease-resistance pathway in a different plant family (Brassicaceae).
\end{abstract}

Additional keywords: autoactive resistance, NB-ARC domain.

Plant disease resistance frequently depends on recognition of invading pathogens and activation of defense mechanisms. Recognition is most commonly determined by a specific plant resistance $(R)$ gene and a corresponding avirulence $(A v r)$ gene in the pathogen, suggesting that the $\mathrm{R}$ protein interacts with the product of the Avr gene (Ellingboe 1981), although such interactions have been demonstrated experimentally for only three R/Avr protein interactions (Deslandes et al. 2003; Jia et al 2000; Scofield et al 1996; Tang et al 1996). Another model is that R proteins "guard" or monitor pathogen-induced changes in the presumptive normal cellular targets of Avr proteins that have a likely virulence role in the absence of specific host $R$ genes (Dangl and Jones 2001; van der Biezen and Jones

Current address of P. Howles: Research School of Biological Sciences, Australian National University, Canberra ACT 0200, Australia

Corresponding author: J. Ellis; CSIRO, Plant Industry, GPO Box 1600, Canberra ACT 2601, Australia, +61 262465421 Phone, +61 26246 4950; E-mail: jeff.ellis@csiro.au
1998). At least three cases of $\mathrm{R}$ proteins guarding host proteins have been documented (Axtell and Staskawicz 2003; Mackey et al. 2003; Shao et al. 2003). In either model, the specific direct or indirect interaction of the $\mathrm{R}$ and Avr proteins activates plant defense responses. About 47 plant disease-resistance genes (i.e., genes with a demonstrated resistance function) have been cloned from different plant species. Of the five distinct classes of resistance protein that have been identified (Dangl and Jones 2001), the largest group (at least 40 genes so far) is the nucleotide binding site-leucine rich repeat (NBS-LRR) class. This class is divided into two groups based on whether the $\mathrm{N}$ terminal domain has a predicted coiled-coil (CC) structure or toll-interleukin-1 (TIR) homology. L6 from flax, a member of the second group (Lawrence et al. 1995), is the focus of this study.

Three short amino acid sequence motifs, the kinase-1a or Ploop (phosphate-binding loop), kinase-2, and kinase-3 motifs, characteristic of previously defined proteins that hydrolyze ATP or GTP (Traut 1994), occur in the NBS domain of resistance proteins, and hydrolysis of ATP has been demonstrated experimentally for two NBS-LRR proteins, I2 and Mi (Tameling et al. 2002). At least five additional amino acid motifs of unknown function are conserved in the NBS region of NBS-LRR proteins and occur between the kinase-3 motif and C-terminal domain LRR (Collins et al. 1998; Grant et al. 1995; Lawrence et al. 1995). Kinase-1a, kinase-2, and kinase-3 and at least some of the additional $\mathrm{R}$ protein-conserved motifs are also present in the same relative order in the animal proteins APAF1 and CED-4, which are involved in regulation of cell death (Chinnaiyan et al. 1997, van der Biezen and Jones 1998), and the central NBS domain of these animal and plant proteins has been referred to as the NB-ARC (nucleotide binding-Apaf1resistance-CED4) (van der Biezen and Jones 1998) or ApATPase (apoptotic-ATPase) (Aravind et al. 1999) domain. The most C-terminal of the conserved plant resistance gene motifs has been termed motif 5 (van der Biezen and Jones 1998) or the MHD (methionine-histidine-aspartate) domain (Bendahmane et al. 2002; Collins et al. 1998). A similar sequence (LHD) occurs in Apaf-1, but is not clearly evident in CED-4 (van der Biezen and Jones 1998), and is not detected in the mammalian NBSLRR proteins CARD4, NOD1, or NOD2 (Bertin et al. 1999; Inohara et al. 1999; Ogura et al. 2001).

Activation of resistance proteins in plants by infection with pathogens expressing corresponding avirulence genes commonly induces localized cell death (the hypersensitive response $[\mathrm{HR}]$ ) as part of the resistance response. This lethal capacity of resistance proteins clearly needs to be tightly regulated in the absence of pathogens. Two current models for this 
regulation, based on strong experimental evidence, involve folding of $\mathrm{R}$ proteins into inactive forms through either intramolecular interactions (cis repression) (Hwang and Williamson 2003; Moffett et al. 2002) or inhibition of R protein activity via binding of repressor proteins (trans repression), for example RIN4 to the RPS2 resistance protein (Axtell and Staskawicz 2003; Mackey et al. 2003). Both forms of repression could act simultaneously in any one resistance protein. The presence of the pathogen avirulence protein is postulated to directly or indirectly activate $\mathrm{R}$ proteins through induced conformational changes (Moffett et al. 2002). This could happen by Avr protein-dependent interruption of repressive intramolecular interactions. by releasing or degrading a bound trans repressor, or both. These cis- and trans-repressive interactions can also be disrupted by mutations that lead to constitutive expression of plant defense responses (autoactivity). Instances of autoactivity of various NBS-LRR proteins, that is activity in the absence of a pathogen or avirulence gene product, have so far been described for at least nine point mutations in different domains of several NBS-LRR proteins (Bendahmane et al. 2002; Shirano et al. 2002; Zhang et al. 2003). Autoactivation can also occur through mutation of resistance protein-specific trans-acting repressor genes (Axtell and Staskawicz 2003; Mackey et al. 2003; Yang and Hua 2004). A third way to autoactivity of $\mathrm{R}$ proteins is through overexpression of $R$ genes (Bendahmane et al. 2002; Grant et al. 2003; Mindrinos et al. 1994; Oldroyd and Staskawicz 1998; Stokes and Richards 2002; Stokes et al. 2002; Tao et al. 2000), which may titrate trans-acting repressors or increase beyond an activity threshold the steady-state level of $\mathrm{R}$ protein molecules, a proportion of which may exist in a spontaneously active state (Tao et al. 2000). Theoretically, mutations in $\mathrm{R}$ proteins that cause substantially increased protein stability could have the same effect.

Using transient expression analysis, Bendahmane and associates (2002) demonstrated that mutation of the MHD motif to MHV in the NBS domain of the virus resistance protein Rx of potato-initiated cell death in the absence of the corresponding avirulence gene product, the coat protein of the Potato virus $X$. This suggested that the MHD motif has a role in repressing defense activation and plant cell death in the absence of the avirulence protein. In the present report, we describe a more extensive analysis, including transgenic plant analysis, of the MHD motif in the flax L6 protein. We also examined the function of a highly variable approximately 20 -residue region that occurs C-terminal to the resistance specificity-controlling LRR region in the products of 10 sequenced flax $L$ alleles (Ellis et al. 1999), and a role for this region in repressing L6 activity is also demonstrated.

\section{RESULTS}

\section{The MHD motif is highly conserved in all plant NBS-LRR proteins.}

We examined the amino acid sequences encoded by 40 of the currently known (March 2004) NBS-LRR disease-resistance proteins for conservation of the MHD motif. The motif was identified in all the NBS-LRR proteins (Fig. 1) using the L6 and RPM1 motifs as comparators and The National Center for Biotechnology Information (NCBI) website's Blast 2 program (Altschul et al. 1990) to align sequences. The identification of the MHD motif in each protein was supported by its conserved position relative to the other NBS region conserved motifs. The first three positions, the MHD tripeptide, are highly conserved, the first position being methionine or other aliphatic residues (I, V, L), the second position, histidine, is invariant, and the third position is most frequently aspartic acid. Ten of the 40 proteins, RPS2, Pi-ta, Lr10, RRS1-R, RPP4, RPP5,
RPP11-A, RPP11-B, RPP11-C, and Gro1-4, do not contain the aspartate residue in position 3 , and four of these exceptions carry an asparagine residue. The MHD sequence is normally followed in positions 4 and 5 by two aliphatic residues, which are commonly identical in any given protein, while the seventh residue is most frequently negatively charged, with aspartate again being the preferred residue. In some cases among the non-TIR class, the MHD triplet is part of a perfect or imperfect direct repeat, for example Xa1 (MHDxMHD, $\mathrm{x}$ is a hydrophobic amino acid) and Hero (VHDxVHD). The sequence alignments also show that positions 9,10 , and 12 are also conserved in the TIR group, and so the MHD motif is presented as a 12-amino acid region in Figure 1.

\section{Some mutants of the MHD motif}

\section{of $L 6$ induce plant cell necrosis in transient assays.}

A set of seven mutants in the MHD motif of the full genomic clone of L6 (M539K, H540A, D541V, N, R, S, and L; henceforth $L 6 K H D, L 6 M A D, L 6 M H V, L 6 M H N, L 6 M H R, L 6 M H S$, and $L 6 M H L$; Fig. 2A) was tested in a transient Agrobacterium infiltration assay in flax cotyledons and Nicotiana benthamiana leaves. The responses of cotyledons of flax line Ward to mutant and wild-type $L 6$ genes are shown in Figure $3 \mathrm{~A}$. In Ward, the wild-type $L 6$ gene and the $L 6 K H D$ mutant had no visible effect, the $L 6 M A D$ mutant caused mild necrosis and the $L 6 M H V$ mutant caused severe necrosis that first appeared after about six days and was fully developed by 12 days. $L 6 M H N$, $L 6 M H R, L 6 M H S$, and $L 6 M H L$ also induced necrosis in flax although the $L 6 M H N$ mutation had only a mild effect. In $N$. benthamiana, only the $L 6 M H V$ mutation had a clear necrotic phenotype. The reaction took 7 to 14 days to develop in $N$. benthamiana. Because we do not have epitope-tagged alleles or antibodies against the L6 protein, we are unable to determine whether the quantitative differences between the mutant alleles is due to differences in stability between the mutant proteins.

Necrosis was dependent on T-DNA transfer from Agrobacterium strains to the plant cell. No necrosis was induced by the MHV mutant when the transformation vector was in an Agrobacterium strain that lacked the vir genes involved in T-DNA processing and transfer to the plant cell (data not shown). Necrosis in both flax cotyledons and $N$. benthamiana leaves also depended on the wild-type P-loop in L6. A K271M mutation in the P-loop of $L 6 M H V$ did not induce necrosis. The result of the transient assays in $N$. benthamiana leaves is shown in Figure $3 \mathrm{~B}$. Necrosis was not induced by the $L 6 M H V$ allele from which the LRR region was deleted (data not shown). So far, we have been unsuccessful in immuno-detection of L6 protein or in expressing epitope-tagged L6 proteins, and so we cannot determine whether the deletion of the LRR has led to protein instability. However, the requirement of the $L 6$ LRR region for necrosis is consistent with previous observations made with the $\mathrm{Rx}$ resistance protein in which epitope-tagged and stable $\mathrm{Rx}$ MHV mutant protein is inactive when the LRR is removed (Moffett et al. 2002).

All the experiments described above were carried out with the genomic clone of $L 6$ expressed from its own promoter. The assay was also done in flax cotyledons and $N$. benthamiana with the wild-type L6 gene and the D541V mutant expressed using the $35 \mathrm{~S}$ Cauliflower mosaic virus (CaMV) promoter. The mutant and wild-type genes were either derived from a genomic clone (three introns present) or a cDNA clone (no introns). In these experiments, the 35SL6 MHV gene induced extensive necrosis 1 to 2 days faster than the construct with the L6 promoter. The wild-type $35 S L 6$ gene also induced some, although much less, necrosis than the mutant but only when the introns were present. This indicates that overexpression of the 
wild-type $L 6$ gene with the strong $35 \mathrm{~S}$ CaMV promoter can also induce necrosis. This observation is consistent with other reports of the effect of expressing NBS-LRR genes with strong promoters (Bendahmane et al. 2002; Mindrinos et al. 1994; Tao et al. 2000).

Two other $L$-gene variants were shown to induce a necrotic response in transient assays. The first, the domain swap construct $\mathrm{L6}-\mathrm{L} 2 \mathrm{H} / \mathrm{Bgl}$ (expressed with the L6 gene promoter) in which the variable region of $L$ alleles (Ellis et al. 1999) that occurs C-terminal to the LRR domain was exchanged between $L 6$ and $L 2$ (Fig. 2B). This construct induced necrosis in N. tabacum in transient expression assays (Fig. 3C) and in flax cotyledons (data not shown). An equivalent swap involving L6 and $\mathrm{LlO}(\mathrm{L6}-\mathrm{LIO} \mathrm{H} / \mathrm{Bgl})$ did not induce necrosis. The second necrosis-inducing variant 35 SL10 short, described previously (Frost et al. 2004), expresses a gene that encodes the TIR ho-

\begin{tabular}{|c|c|c|}
\hline \multicolumn{3}{|c|}{ Non-TIR class } \\
\hline Rpm1 & CAA61131 & MHDVIWEIALSV \\
\hline Rps 5 & AAC26126 & MHDVVREMALWI \\
\hline I2 & AAD27815 & MHDLVNDLAQLA \\
\hline Rp1D & AAD47197 & MHDILHDFAESL \\
\hline $\mathrm{RPP} 8 / \mathrm{HRT}$ & AAC83165/AAF36987 & REV \\
\hline $\mathrm{Rx} / \mathrm{Gpa} 2$ & CAB50786/AAF04603 & MHDVTRELCLRE \\
\hline Dm3 & AAD03156 & MHDLVRAFVLGM \\
\hline Xa1 & BAA25068 & MHDLMHDLAQKV \\
\hline RB/Rpib1b & AAP45164/AAR29069 & HDLIHDLZ \\
\hline Mla1 & AAG37356 & VHDMVLDLI \\
\hline Pib & BAA76281 & VHDLMRDIAISK \\
\hline $\mathrm{Sw}-5$ & AAG31014 & VHDVVHHFCLEK \\
\hline Hero & CAD29729 & JHDVVHDECSVK \\
\hline Bs2 & AAF09256 & VHDLIYDLCVRE \\
\hline $\mathrm{R} 1$ & AAL39063 & LHDVLLDFCKER \\
\hline Pm3b & AAQ96158 & IHDLMHDIAMSV \\
\hline $\mathrm{Tm}-2(2)$ & AAQ10735 & $\mathrm{HSLC}$ \\
\hline Mi1 & AAC67238 & IHDLVHDFCLIK \\
\hline Prf & AAC49408 & IHDLLHKFCMEK \\
\hline Rpp13 & AAF42830 & LRDVAIKK \\
\hline $\operatorname{Lr} 21$ & AAP74647 & LHDLLVKV \\
\hline $\operatorname{Rpg} 1-B$ & AAR19095 & LNDLF \\
\hline Rps2 & AAA2 1874 & VRSFALWM \\
\hline Lr10 & AAQ01784 & ILDFLMIK \\
\hline Pi-ta & AAK00132 & HMVLNFIRCK \\
\hline TIR clas & & \\
\hline $\mathrm{N}$ tob & A54810 & \\
\hline $\mathrm{L} 6 / \mathrm{M}$ & AAA91022/AAB47618 & \\
\hline $\mathrm{N}$ flax & CAC35321 & TDT.GRA \\
\hline Rps 4 & CAB50708 & YYKESRE \\
\hline Bs 4 & AAR21295 & RDMGRY \\
\hline P2 & AAK28806 & 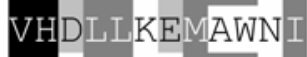 \\
\hline Rpp4/5 & AAM18462/ AAF08790 & \\
\hline $\operatorname{Rpp} 1 \mathrm{~A} / \mathrm{B} / \mathrm{C}$ & AAC72977 & EQFGRE \\
\hline RRS-1R & Q9FH83 & 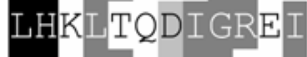 \\
\hline Gro1-4 & AAP44390 & IHQL IQDMGWHI \\
\hline
\end{tabular}

Fig. 1. Alignment of the extended methionine-histidine-aspartate (MHD) motif regions in 40 cloned nucleotide binding site-leucine rich repeat gene products with identified resistance activity (as of March 2004). NCBI protein database accession numbers are provided for access to full details and publication references of the genes. All RPP4 paralogs are listed under the same accession number. The RB/Rpi-blb1 genes are the same gene cloned independently. Other genes listed on the same line are orthologues with different resistance specificities. The Tobacco mosaic virus resistance protein $\mathrm{N}$ is listed as ' $\mathrm{N}$ tob' to distinguish it from the flax rust resistance protein $\mathrm{N}$. The proteins have been divided into two groups containing the non-toll interleukin 1 receptor (TIR) class and N-terminal TIR class. Shading indicates the level of conservation at each site (black $=100 \%$, dark gray $>80 \%$, light gray $>60 \%$ ) with amino acid residues of similar chemical properties (aliphatic, aromatic, polar, basic, acidic) considered together. 
mology region and 17 amino acids of the NBS region of $L 10$ and induced a strong necrotic reaction in tobacco leaves (Frost et al. 2004) and in the flax cotyledon assay in the present study (data not shown).

\section{Analysis of autoactive alleles of L6 in transgenic flax.}

The $L 6 K H D, L 6 M A D$, and $L 6 M H V$ mutant alleles and the $L 6-L 2 H / B g l$ and $L 6-L 1 O H / B g l$ domain swaps were tested in transgenic flax. All these constructs contained the $L 6$ promoter. Ten transgenic plants containing the $L 6 K H D$ mutant allele and their selfed progeny had normal morphology and were susceptible to infection with a rust strain avirulent to $L 6$. Although reverse transcriptase-polymerase chain reaction (RT-PCR) analysis indicated that the mutant genes were expressed (data not shown), the encoded protein is either nonfunctional or unstable.

Six of seven $L 6 M A D$ T0 transgenic plants had a dwarf phenotype and their T1 progeny segregated for normal, dwarf, and extreme dwarf plants. The dwarf phenotypes were identical to those shown in Figure 4A and were associated with decreased internode lengths (Fig. 4B and C). Analysis of T2 progeny families from these plants demonstrated that the T1 dwarfs and extreme dwarfs were hemizygous and homozygous, respectively, for the dwarfing gene. T1 progeny were tested for reaction to a rust strain avirulent to $L 6$. In the analysis of rust resistance of the T1 progeny families (59 seedlings) there was a complete association between rust resistance and the dwarf phenotypes, which indicated that the dwarf phenotype and resistance were caused by the $L 6 M A D$ transgene. For example, nine progeny of the T0 plant $\mathrm{PH} 253-3$ segregated two wildtype (rust susceptible), four dwarf (resistant), and three extreme dwarf (resistant) seedlings. In a second experiment, a further 10 progeny of the T0 plants were tested with a rust strain virulent to L6. Wild-type segregants were susceptible and dwarfs and extreme dwarfs were resistant. The resistance reaction of dwarfs to $L 6$-avirulent and $L 6$-virulent strains could be distin- guished. Reaction to the former rust involved HR and no rust sporulation, whereas reaction to the latter was tiny sporulating rust pustules on young leaves and complete resistance with HR on older leaves (Fig. 4F). The extreme dwarfs were completely resistant. No spontaneous HR was observed in noninoculated dwarf plants (Fig 4E). Either the L6MAD mutant has gained a new resistance specificity (toward a rust strain that does not possess avirulence to $L 6$ ) or the observed resistance is not due to normal gene-for-gene recognition. Data below suggest that rust resistance to $L 6$-virulent rusts is most likely due to autoactivity of the mutant $L 6$ allele giving rise to constitutively expressed defense responses. Images of the dwarf phenotypes and rust reactions of plants transgenic for autoactive $L 6$ alleles, either $L 6 M A D$ or $L 6-L 2 / H i n \mathrm{~d} / B g 1$ (discussed below), are shown in Figure 4.

We had difficulty in recovering transgenic plants carrying the $L 6 M H V$ allele that was the most active in induction of cell death in transient assays. Only five transgenic plants were recovered from multiple transformation experiments. Three had a normal phenotype, were susceptible to rust, and possibly did not express the mutant gene. Two had a dwarf phenotype in the T0 generation that was more extreme than any L6MAD transgenics or their progeny. These T0 plants became chlorotic during growth in soil and were maintained as cuttings, many of which died due to severe leaf necrosis spreading upward from the base of the plant before seed production. Five progeny recovered from a single seed capsule segregated one normal, three dwarfs, and one extreme dwarf that died before flowering. None of the $L 6 M H V$ progeny have been tested for rust reaction because of their extreme phenotype and poor growth.

Seven of eight T0 $\mathrm{L6}-\mathrm{L} 2 \mathrm{H} / \mathrm{Bgl}$ transgenics were resistant to a rust strain that is avirulent to $L 6$ and expressed no obvious abnormal growth phenotypes. Progeny of three rust-resistant transgenics had a wild-type phenotype, while the four others segregated for a dwarf phenotype. These four carried a single transgene insert (DNA gel blot analysis, data not shown).

A

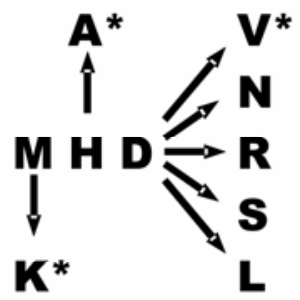

B

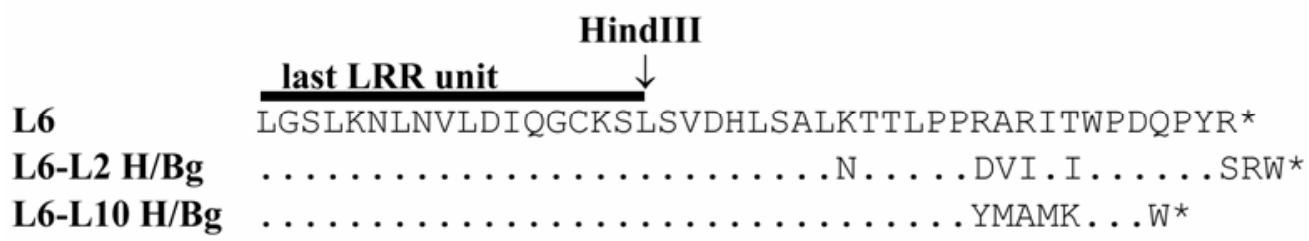

Fig. 2. A, Mutations introduced by site-directed mutagenesis into the methionine-histidine-aspartate (MHD) motif of L6. The mutations marked by an asterisk were tested in both transient assays and in transgenic flax. B, The amino acid sequences of the C-terminus of L6 protein and L6-L2 H/Bgl and L6L10 H/Bgl domain swaps that replace the C-terminal polymorphic residues of L6 with those of L2 and L10. The position of the HindIII restriction enzyme cleavage site in the corresponding DNA sequence and used for construction of the recombinants is shown. The BglII restriction site used for making the exchanges occurs $3^{\prime}$ of the stop codon of each allele. 
Progeny from three of these four transgenics segregated consistent with a 3:1 ratio (e.g., T0 plant JE3170, discussed below, 46 wild-type and 18 dwarfs-dwarfs were homozygous for $\mathrm{L6}-\mathrm{L} 2 \mathrm{H} / \mathrm{Bgl}$ ). The fourth family (from T0 plant JE3192) segregated for 15 wild-type, 35 dwarf, and 18 extreme dwarf, consistent with a 1:2:1 ratio in which individuals hemizygous for the transgene are dwarf and those homozygous for the transgene have an extreme dwarf phenotype. This was similar to L6MAD mutants. The fact that progeny from three of the seven T0 L6-expressing transgenics did not segregate for the dwarf phenotype and only one of the four remaining families segregated for the extreme dwarf phenotype indicates that the L6$\mathrm{L} 2 \mathrm{H} / \mathrm{Bgl}$ allele is a weaker autoactive allele than the $L 6 M A D$ and $L 6 M H V$ mutants in stable transgenics. Primary transgenic plants expressing the domain swap allele $\mathrm{L} 6-\mathrm{L} 1 \mathrm{OH} / \mathrm{Bgl}$ did not express rust resistance and had no unusual growth phenotypes.

To test the rust-resistance specificity of the $L 6-\mathrm{L} 2 \mathrm{H} / \mathrm{Bgl}$ transgene and to confirm the association of the transgene with the dwarf phenotype, seven to ten progeny groups from two primary transgenics (JE3170 and JE3192) were each tested with several rust strains either avirulent or virulent to $L 6$ plants. In tests with L6-avirulent rust strains, the JE3170 fami- lies segregated 19 wild-type plants (14 rust resistant, 5 susceptible) to 8 dwarf plants (all resistant), consistent with the dwarf plants being homozygous for the transgene and with the phenotypically wild-type plants being either hemizygous for the transgene (and resistant) or lacking the transgene (susceptible) in a 2:1 ratio. With $L 6$-virulent rusts, this family segregated 21 normal (all rust susceptible) to 6 dwarf (all resistant). This result indicated that the resistant wild-type plants expressed the L6 specificity, whereas the dwarf plants, like L6MAD dwarfs, expressed a nonspecific resistance. In contrast to the normal L6 rust-resistance phenotype with no pathogen development, the resistance of the dwarf plants to $L 6$-virulent strains was slightly "leaky" in that the younger inoculated leaves produced small uredospore pustules surrounded by necrosis. The other older leaves produced hypersensitive flecks and no apparent rust growth. Rust reactions of $L 6-\mathrm{L} 2 \mathrm{H} / \mathrm{Bgl}$ leaves are shown in Figure 4. The rust reactions of $L 6-L 2 H / B g l$ plants are very similar to those of $L 6 M A D$ plants.

Families from JE3192, tested with an L6-avirulent rust, segregated 6 normal (all susceptible), 12 dwarfs (all resistant), and 7 extreme dwarfs (all resistant), which also demonstrated a clear association between the presence of the resistance-con-
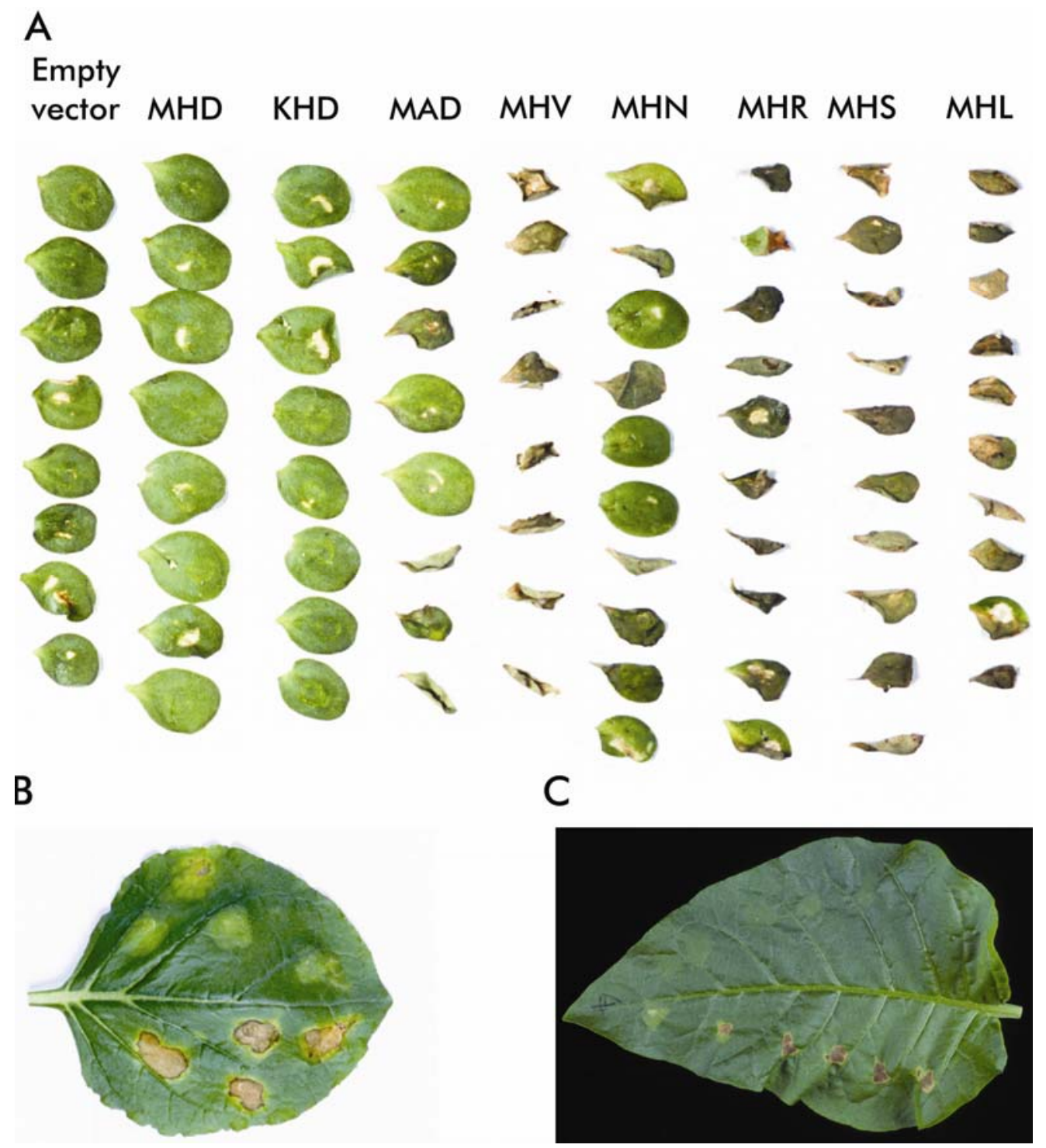

Fig. 3. A, Reaction of flax cotyledons to infiltration with Agrobacterium strains containing the 'empty' binary vector and the same vector carrying the indicated $L 6 M H D$ mutants. B, A leaf of $N$. benthamiana infiltrated with $L 6 M H V$ (bottom) and $L 6 M H V$ with a mutated P-loop (top). C, A leaf of $N$. tabacum infiltrated with $L 6-L 2 H / B g l$ (bottom) and the empty vector (top). Infiltration with wild-type $L 6$ gave reactions very similar to the empty vector (not shown). 
ferring transgene and a dwarf phenotype. When tested with L6virulent rusts, progeny segregated 6 normal (all susceptible), 18 dwarf (all resistant), and 9 extreme dwarf (all resistant).

\section{Basis of nonspecific rust resistance.}

The rust strains used in this analysis were selfed progeny of strain CH5 (Lawrence et al 1981). Avirulent strains carry two linked avirulence genes, AvrL567- $a$ and AvrL567- $b$, that are recognized by $L 6$, whereas virulent strains are homozygous for the polymorphic, expressed-but-unrecognized gene AvrL567-c, and these genes encode very similar proteins (Dodds et al. 2004). We tested whether the L6MAD and L6-L2Hind/Bgl autoactive alleles may have gained recognition for the AvrL567-c gene product in the L6-virulent strains. Using a transient Agrobacterium infiltration assay (Dodds et al. 2004), we introduced a control empty vector construct, AvrL567-a, expressed from the $35 \mathrm{~S}$ promoter, and AvrL567-c, expressed from the same promoter, into $L 6, L 6 M A D, L 6-L 2 H i n d / B g l$, and rust-susceptible Ward flax plants. No leaf necrosis was induced in the susceptible Ward plants. Necrosis was induced by AvrL567- $a$ but not by AvrL567-c in L6 leaves, consistent with a specific gene-for-gene interaction. A similar result was observed for the $L 6-L 2 \mathrm{H} / \mathrm{Bgl}$ dwarf plants, although the necrotic reaction to AvrL567- $a$ was slower to develop and less extensive, which also indicated $L 6$ specificity. For the $L 6 M A D$ plants, no necrosis was induced by either AvrL567- $a$ or AvrL567-c. The weaker response to AvrL567- $a$ by the autoactive $L 6-L 2 \mathrm{H} / \mathrm{Bgl}$ plants, which express $L 6$ specificity, may be due to increased resistance to Agrobacterium infection due to expression of defense responses in these plants (discussed below). The failure of $L 6 M A D$ plants to recognize AvrL567- $a$ may be due to either the effects of the defense gene expression on Agrobacterium growth, the loss of $L 6$ specificity by the mutant, or both. The former possibility at least is supported by the
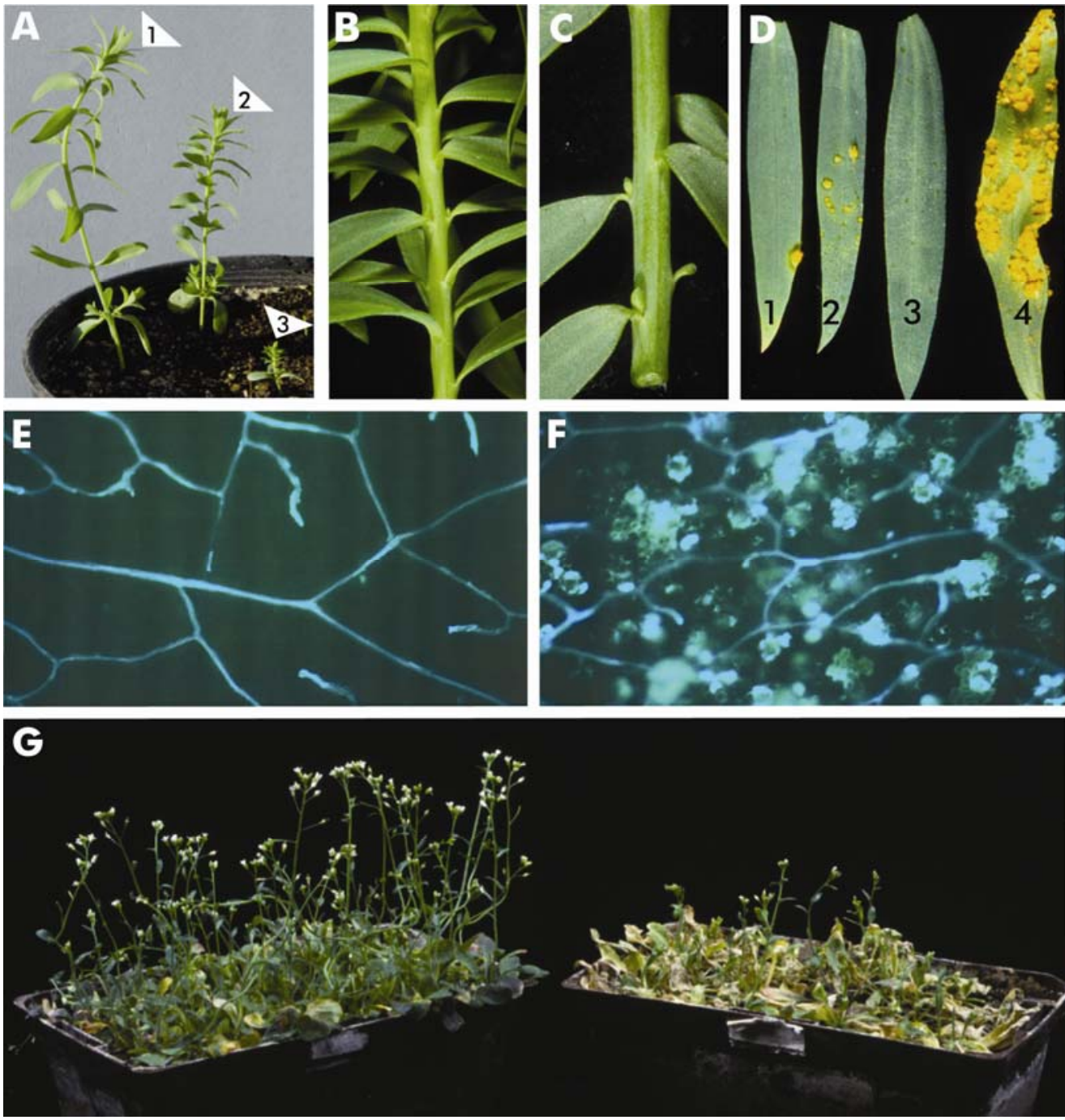

Fig. 4. A, T1 progeny of a transgenic flax plant JE3192 that carried a single copy of the L6-L2H/Bgl transgene. Progeny segregate for wild type (plant 1 , transgene null), dwarf (plant 2, hemizygote), and extreme dwarf (plant 3, transgene homozygote) phenotypes. The phenotypes of $L 6 M A D$ segregants are identical, while the dwarf and extreme dwarf segregants of $L 6 M H V$ transgenics are more extreme. B and $\mathbf{C}$, Similar length stem segments of dwarf (B) and wild-type (C) T1 segregants derived from a plant transgenic for the L6MAD mutant allele. Dwarf plants have reduced internode lengths. D, Leaves 1, 2, and 3 are from a dwarf segregant derived from transgenic plant JE3912 and have been photographed approximately 14 days after inoculation with rust strain CH5F2-78 that is virulent to plants carrying L6. Leaves 1 and 2 are younger and show some small pustules, while the oldest leaf 3 showed hypersensitive flecks. Leaf 4 is derived from a control infection of a plant with no effective rust resistance gene. $\mathbf{E}$ and $\mathbf{F}$, The detection of autofluorescence associated with the hypersensitive response reaction in uninfected mock-inoculated and rust-infected leaves, respectively, from progeny plants transgenic for the $L 6 M A D$ allele. The rust strain used was virulent to $L 6$. The leaves were cleared and viewed under a microscope with UV source to detect autofluorescence and were photographed five days after rust infection. No autofluorescence was seen in compatible rust interactions with wild-type plants (data not shown). G, Transgenic Arabidopsis (approximately 4 weeks after germination) carrying alcA-L6 (left) and alcA-L6 MHV (right) were sprayed with $2 \%$ ethanol and were photographed five days after treatment. 
observation of much-reduced transient-expression $\beta$-glucuronidase (GUS) activity in $L 6 M A D$ plants compared with $L 6$ plants when infiltrated with an Agrobacterium strain with a T-DNA carrying 35SGUS.

In Arabidopsis, mutants that constitutively express suites of defense proteins, including PR1 and chitinase, frequently have stunted phenotypes (Bowling et al. 1997; Grant et al. 2003; Shah et al. 1999; Shirano et al. 2003; Zhang et al. 2003). We examined some of the dwarf flax lines for constitutive expression of PR1 mRNA and chitinase enzyme activity. T1 progeny of the L6MAD transgenic plant $\mathrm{PH} 253-3$, which, as shown by DNA gel bot analysis, contained a single transgene insert, were grown in soil, were scored for dwarf phenotype, and were used for RNA preparation. Two wild-type, three dwarf, and three extreme dwarf progeny (nontransgenic, heterozygous, and homozygous, respectively, for the transgene, as determined subsequently by $\mathrm{T} 2$ family analysis) were examined by RNA gel blot analysis of the PR1 gene (Fig. 5A). Very low levels of PR 1 expression were detected in the wild-type segregants (transgene nulls), and increased levels of PR1 message were detected in the dwarf (transgene heterozygotes) and extreme dwarf (homozygous) progeny. Expression levels of PR1 in the transgene hemizygotes and homozygotes were approximately 10- and 100-fold higher than the nontransgenics, respectively, indicating an amplification of the response by the increase from one to two transgene copies.
A

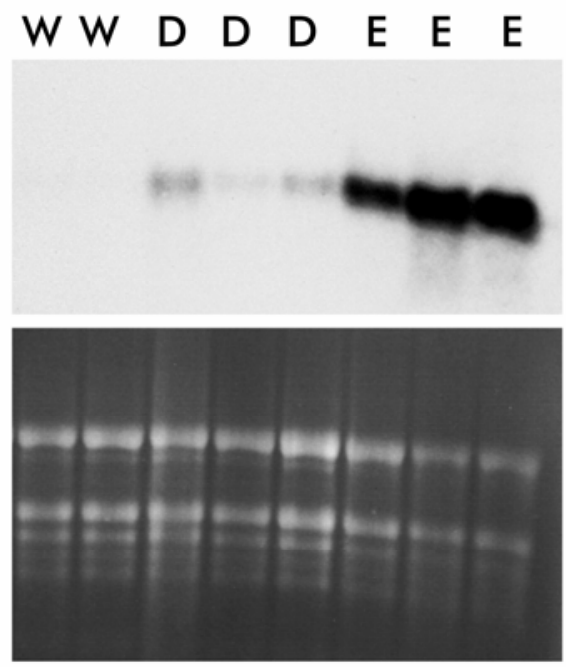

B

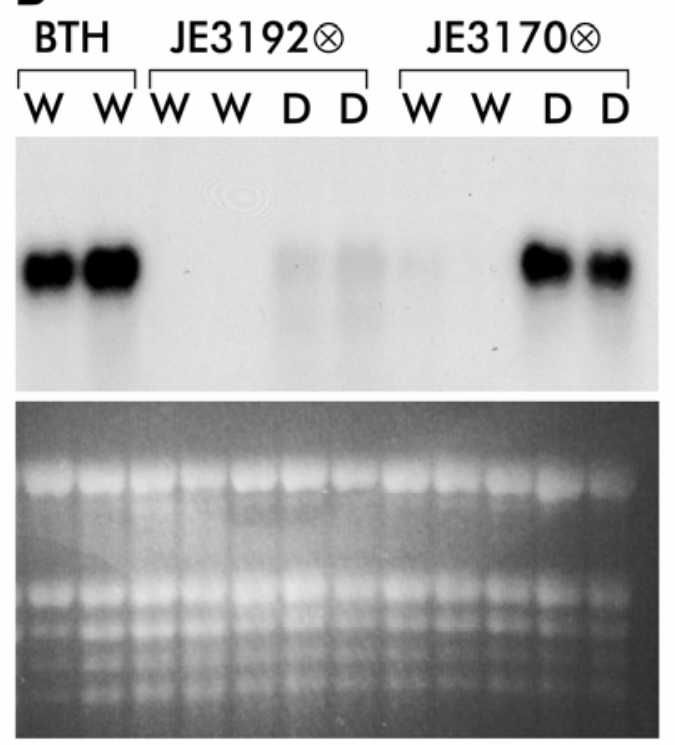

C

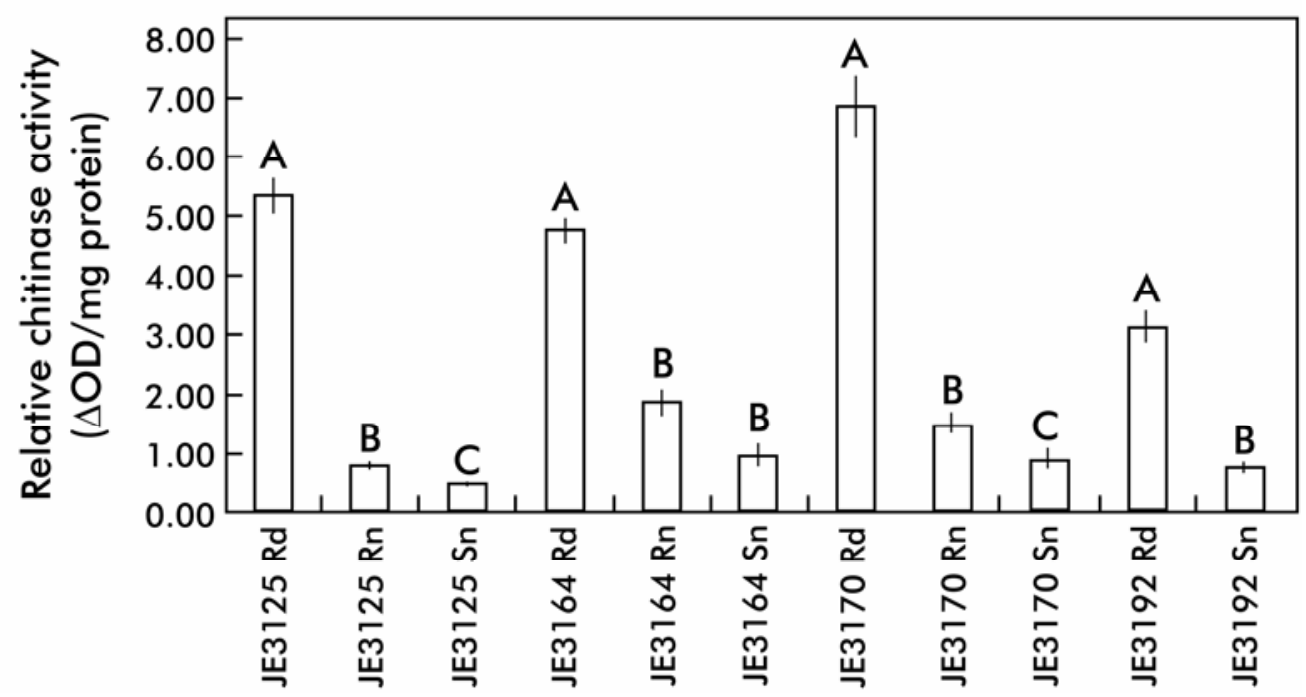

Fig. 5. Pathogenesis-related (PR) gene and chitinase expression in autoactive L6 flax. A, T1 segregants derived from selfing a transgenic plant PH253-3 carrying a single copy of $L 6 M A D$ allele. Equal amounts (optical density at $260 \mathrm{~nm}$ units) of RNA extracted from two wild-type (W) segregants, three dwarf (D), and three extreme dwarf segregants (E) were probed with a flax PR1 gene probe. The ethidium bromide-stained gel provides the loading control. B, Equal amounts of RNA from wild-type (W) and dwarf segregants (D) of two transgenic flax plants carrying the $L 6-\mathrm{L} 2 \mathrm{H} / \mathrm{Bgl}$ allele and from wild-type plants sprayed with benzothiadiazole-7-carbothioic-acid-S-methyl ester (BTH) were probed with a flax PR1 gene probe. The extreme dwarf progeny from JE3192 were not examined in this experiment, and JE3170 segregated for only wild-type and dwarf progeny. C, Chitinase activities were determined for segregating progeny from four different $\mathrm{L} 6-\mathrm{L} 2 \mathrm{H} / \mathrm{Bgl}$ plants. Plants were classified as dwarf (d) or wild-type (n) by visual inspection and rust resistant (R) or susceptible (S) by inoculation of individual plants with flax rust after tissue samples had been taken for chitinase assays. Extreme dwarf progeny of JE3192 were not examined. Within JE3125, JE3170, JE3192, and JE3164, chitinase activities marked with different letters are significantly different ( $t$-test, $95 \%$ confidence). 
T1 dwarf and wild-type progeny of the $L 6-L 2 H / B g l$ plants JE3192 and JE3170 were examined for PR1 expression by RNA gel blot analysis (Fig. 5B). For JE3192 progeny, a small increase in the level of PR1 expression was observed in dwarfs. RNA was not isolated from the extreme dwarfs (probable transgene homozygotes) that segregated in the JE3192 family. Higher levels of PR1 expression occurred in the JE3170 dwarf progeny (presumed transgene homozygotes), and this expression was equivalent to the level induced in wild-type flax seedlings by spraying with $0.16 \mathrm{mM} \mathrm{1,2,3,-ben-}$ zothiadiazole-7-carbothioic-acid-S-methyl ester (BTH) (Fig. $5 B)$.

Progeny of four different $L 6-L 2 H / B g l$ primary transgenics were tested for chitinase enzyme activity (Fig. 5C). In this experiment, we measured chitinase activity in each progeny seedling and then determined the presence or absence of the L6- $L 2 \mathrm{H} / \mathrm{Bg}$ l transgene in that seedling by testing its reaction to a rust strain avirulent to $L 6$ (Fig. $5 \mathrm{C}$, $\mathrm{R}$ or $\mathrm{S}$ ). The dwarf progeny expressed at least fourfold more chitinase activity than the nontransgenic normal progeny. The heterozygous nondwarf progeny expressed a small increase in chitinase expression over the nontransgenic controls (Fig. 5C). Only the heterozygous dwarf and not the extreme dwarf progeny of JE3192 were tested.

Based on the observed increase in PR1 gene expression and chitinase activity in the dwarf plants, we postulate that the increased spectrum of resistance of these transgenics to rust strains normally virulent to L6 plants is probably not due to classic resistance gene-avirulence gene interaction but rather to autoactivation of plant defenses (i.e., activity of the R protein in the absence of a corresponding Avr protein).

\section{Expression of autoactive alleles using the flax Fis1 promoter.}

Nonspecific resistance and plant stunting are associated with the autoactive $L 6$ alleles. We attempted (unsuccessfully) to uncouple nonspecific resistance and dwarfing by using a rustinducible promoter to control the expression of the autoactive alleles. The flax Fisl promoter, which is induced around developing rust pustules (Ayliffe et al. 2002), was used to express the $L 6 / L 2 H / B g l$ and $L 6 M H V$ alleles in transgenic flax. Ten Fis 1-L6/L2 H/Bgl transgenics were recovered. The T0 and T1 plants had a wild-type (not dwarf) phenotype, suggesting that the expression of the $L 6 / \mathrm{L} 2 \mathrm{H} / \mathrm{Bgl}$ transgene from the Fis 1 promoter may be less than from the $L 6$ promoter, which is associated with a dwarf phenotype. No nonspecific rust resistance was achieved with this transgene; T1 progeny plants segregated for resistance to a rust strain avirulent to $L 6$ and were fully susceptible to a strain virulent to L6. The Fis1-L6MHV transgene behaved differently. Transgenic plants had a dwarf phenotype and expressed nonspecific rust resistance. We conclude that $L 6 M H V$ is a stronger autoactive allele than $\mathrm{L6} / \mathrm{L} 2 \mathrm{Hind} / \mathrm{Bgl}$ and that the background (uninduced) level of expression from the Fisl promoter (Ayliffe et al. 2002) is sufficient for expression of the dwarf phenotype associated with the $L 6 M H V$.

\section{Expression of autoactive alleles using an ethanol-induced promoter.}

The concept of regulated expression of an autoactive L6 allele was further explored in both Arabidopsis thaliana and flax, using the ethanol-induced alcA/alcR promoter/activator system (Caddick et al. 1998). For Arabidopsis, 21 alcA-L6 and 23 alcA-L6MHV plants were recovered in the background of the Col-0 ecotype. Their transgenic progeny, which had a wildtype appearance, were treated with $2 \%$ ethanol. Progeny of 18 of the 23 alcA-L6MHV plants became necrotic within two to four days of treatment, whereas none of the alcA-L6 plants showed any effects (Fig. 4G). RNA gel blot analysis indicated that $L 6$ mRNA could be detected at $3 \mathrm{~h}$ after a single ethanol treatment, with peak expression around $6 \mathrm{~h}$ posttreatment in both classes of transgenic plant. The expression of the alcA$L 6 M H V$ gene is shown in Figure 6A. In the alcA-L6MHV plants, PR1 gene expression was detected by $24 \mathrm{~h}$ (Fig. 6B).

The alcA- $L 6 M H V$ allele was also tested in ecotype WS-0 and the WS-0 mutant eds $1-5$ (Falk et al. 1999). Progeny of five of seven WS lines died after ethanol treatment. None of the progeny of 10 transgenic eds $1-5$ plants died after ethanol treatment, although four lines showed distinct yellowing. In summary, in both the Col-1 and WS-0 backgrounds, ethanol induced complete necrosis of plants transformed with the alcA-L6MHV allele but had no effect on plants transformed with alcA-L6. The phenotype was dependent on EDS1, although some yellowing was evident in plants carrying eds $1-5$, which is a weak allele of EDS1 (Falk et al. 1999).

Flax was also transformed with the same two ethanol-regulated constructs. Eight alcA-L6 transgenics were recovered. Among the seven T0 plants tested, all were susceptible to an L6-avirulent rust, which indicated no or insufficient expression of the $L 6$ gene to give resistance. T1 progeny from the eight T0 alcA-L6 plants and controls were treated with ethanol. Treatment had no effect on nontransgenic controls. In contrast to the results in Arabidopsis, seven of the eight alcA-L6 T1 flax families segregated for ethanol-induced necrosis that was visible from $12 \mathrm{~h}$ after treatment. Six T0 transgenic flax plants carrying the alcA-L6MHV allele were recovered. The T1 progeny had a wild-type appearance, and only one of the T0 plants produced progeny that segregated for ethanol-induced necrosis that was more rapid and extensive than AlcA-L6 plants.

The difference between experiments with flax and Arabidopsis may be partly due to the transformation method. Transformation of flax involved a callus stage in tissue culture that can induce the anaerobic response that produces ethanol and acetaldehyde (Dolferus et al. 1985), both strong inducers of

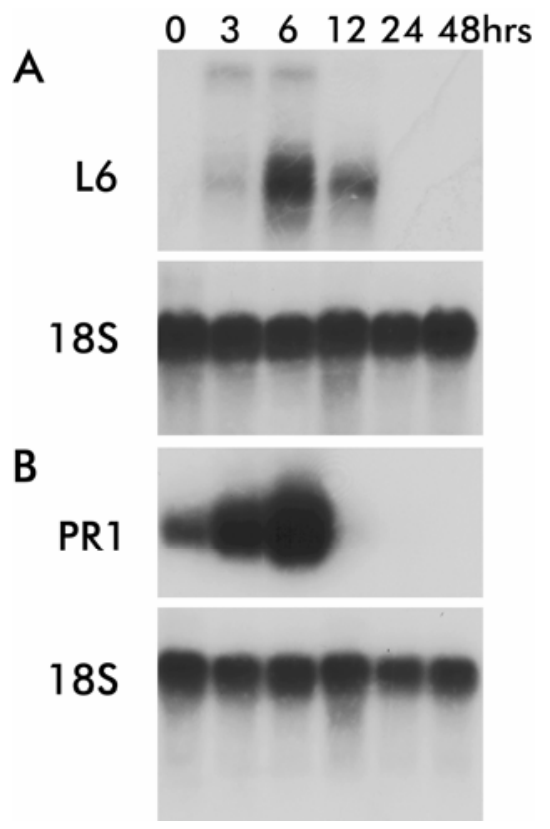

Fig. 6. Ethanol-induced expression of $L 6 M H V$ and $P R 1$ RNA by ethanol treatment in bulked transgenic progeny derived by selfing an Arabidopsis plant transgenic for alcA-L6MHV. RNA was isolated from seedlings at the indicated times after treatment, and two gel blots were made. A, Results using the $L 6$ gene probe. B, Results using the $P R 1$ gene probe. The RNA loading controls shown in A and B were provided by reprobing both filters with an 18S RNA probe. 
the alcA promoter (Junker et al. 2003). Tissue culture induced expression of the strongly autoactive alcA-L6MHV would counter-select transformed cells in the callus. The activity of the alcA-L6 in flax but not Arabidopsis transformants could be due to more effective interaction of the L6 protein with presumptive downstream signaling components in flax as compared with Arabidopsis.

\section{DISCUSSION}

\section{Autoactive L6 mutants.}

Several different autoactive alleles of $L 6$ have been described here. The autoactive domain-swap allele $L 6-L 2 H / B g l$ is reminiscent of the similar effect of $\mathrm{N}$-terminal domain swaps between paralogous $\mathrm{Mi}$ genes in tomato, which disrupt intramolecular interactions that normally repress activity (Hwang and Williamson 2003), and also reminiscent of "lesion mimic" recombinants between paralogues of the maize $R p l$ genes (Sun et al. 2001). The variable C-terminal domains of $\mathrm{L}$ proteins may interact with upstream variable domains in the $\mathrm{L}$ protein and repress activity in the absence of avirulent rust pathogens. Interestingly, while $L 6-\mathrm{L} 2 \mathrm{H} / \mathrm{Bgl}$ has an autoactive phenotype, another domain swap, L6-L2 Sph, with 5' L6 and 3' L2 sequences (Ellis et al. 1999), recombined at a site in the NBS domain, expresses a wild-type $L 2$ resistance and no obvious morphological phenotype. This exchange site may define an $\mathrm{N}$-terminal limit of the upstream site with which the C-terminal domain may interact.

In the present study of $L 6$, we have also extended the earlier observation, made with the Rx resistance protein (Bendahmane et al. 2002; Moffett et al. 2002), that the conserved MHD motif functions as a negative regulator of resistance protein activity. Specifically, we have looked at a larger set of MHD motif mutants and have examined some of these in transgenic plants. The crucial role played by the aspartate residue of the MHD motif of L6 in repression of the R protein was demonstrated by mutation of this amino acid. Substitution of the negatively charged aspartate with an uncharged hydrophobic aliphatic residue (valine and leucine), a positively charged residue (arginine), a small uncharged polar residue (serine), and by the similar asparagine all induced autoactivity. Substitution of aspartate with glutamate that is also negatively charged was not examined in this study; however, we note that in the many predicted NBS-LRR proteins encoded by the Arabidopsis genome, most of unknown function, none carry a glutamate at this position of the MHD motif, suggesting that it cannot functionally substitute for aspartate. The fact that five different substitutions had a similar effect indicates that this conserved motif may be part of a molecular switch and that interaction of the negatively charged aspartate residue with one or more other as-yet-unidentified $\mathrm{R}$ protein residues locks the activity of the protein in the "off" position. Such a situation is known for a $\beta 2$-adrenergic receptor in which arg-131 in a conserved asp-arg-tyr triad is involved in an ionic interaction with the proximal asp-130 and distal glu-268 residue to lock the receptor into the inactive state. This intramolecular interaction was indicated by data from site-directed mutagenesis of the critical residues that cause receptor activation and was further supported by crystallographic analysis of the receptor that shows juxtaposition of the postulated interacting residues in the folded inactive receptor (Ballesteros et al. 2001). A crystallographic analysis of the NB-ARC domain will help to fully elucidate the action of the MHD motif in R proteins. It is interesting to note that, among the 40 cloned $\mathrm{R}$ proteins (Fig. 1), 10 do not carry the aspartate residue and 4 (including orthologues RPP4 and 5) carry asparagine, the substitution that has a mild but detectable necrosisinducing effect on L6 in transient assays. The effects of the substitutions in the six other exceptions (D to H, T, Q, and $\mathrm{K}$ in Pi-Ta, RPP1-A/-B/-C, Gro1-4, and RRS1-R, respectively) have not been tested in the context of L6 or Rx. It may be that the potential autoactivating effects of these exceptions are "compensated" by other sequence differences in the respective $\mathrm{R}$ proteins. Mutation of the completely conserved histidine residue (Fig. 1) to alanine (L6MAD) had a similar but less drastic autoactive effect than L6MHV, as judged by the transient and stable transformation phenotypes. Mutation of methionine to lysine (the $L 6 K H D$ allele) did not cause autoactivation but destroyed L6 activity, either because the M residue is needed for L6 activity or because the substitution destabilizes the protein.

The MHD motif has also been identified by sequence similarity and location in the mammalian cell death-control protein Apaf-1 and occurs as LHDLQVD and is also conserved in the very closely related proteins from zebra and puffer fish. However, no obvious equivalent sequence occurs in the Apaf-1 homologue DARK in Drosophila melanogaster (Rodriguez et al. 1999). As far we are aware, no mutations in the potential MHD-like motif of Apaf-1 have been analyzed to determine whether this sequence is indeed a functional homologue of the plant resistance-protein MHD motif.

For both Rx and L6, autoactivity of mutants in the MHD motif is dependent on the wild-type P-loop and LRR region (Bendahmane et al. 2002; Moffett et al. 2002; this study), indicating that ATP binding (and perhaps hydrolysis) and the LRR region are necessary for activity. However, studies by Frost and associates (2004) and this study indicate that expression of a truncated $L 10$ gene, a closely related allele of $L 6$, encoding essentially only the TIR N-terminal region also induces necrosis in transient assays in flax and tobacco and severe autoactive resistance phenotypes in transgenic tobacco. This result is consistent with the TIR region being the major signaling domain of the TIR-NBS-LRR class of resistance proteins and with this signaling capacity being normally repressed by interactions with the remainder of the wild-type $\mathrm{L}$ protein. Other work (Bendahamane et al. 2002; Hwang and Williamson 2003; Moffett et al. 2002) similarly indicates a signaling role of the $\mathrm{N}$-terminal CC domain of the CC-NBS-LRR class of resistance proteins and the involvement of intramolecular interactions in repressing signaling. Thus derepression of L rust-resistance proteins can be mediated by i) a cognate Avr protein, ii) by mutations, like $L 6 M H V$ in a P-loop and LRR-dependent fashion, iii) sequence changes in the variable $\mathrm{C}$-terminal variable region, and iv) by deletion of the repressing NBS and LRR domains. The data suggest $\mathrm{R}$ proteins are held inactive by intramolecular interactions involving regions including the LRR and MHD and that activation triggered by Avr proteins releases the TIR domain for active signaling.

We have also shown that the autoactive $L 6$ gene induces a cell death response in transient assays in tobacco species and also when expressed from a regulated promoter in transgenic Arabidopsis. L6 autoactivity in transgenic Arabidopsis, like activity of Arabidopsis TIR-NBS-LRR genes, is dependent on the EDS1 gene. Additionally, we have recently demonstrated that the $L 6$ gene interacts in a gene-for-gene manner with its corresponding flax rust $A v r$ gene in transient assays in tobacco (Dodds et al., 2004). Together, these data show that some resistance genes can function in different plant families.

\section{Do autoactive $L 6$ alleles retain $L 6$ specificity?}

The $L 6-L 2 H / B g l$ allele clearly retains $L 6$ gene-for-gene specificity. In those transgenic lineages where the autoactive phenoltype is not expressed and in transgene heterozygotes of the JE3170 lineage that have a wild-type stature, transgenic plants are resistant to $L 6$-avirulent rusts and susceptible to $L 6$-viru- 
lent rusts. For $L 6 M A D$ plants, the conclusion is less clear. Because the reactions of $L 6$ and $L 6 M A D$ plants to avirulent rusts is identical (minute HR flecks and no rust sporulation) and the reactions of $L 6 M A D$ plants to $L 6$-avirulent and $L 6$-virulent rust strains can be distinguished on younger leaves on the basis of the amount of rust uredospore formation and chlorosis, we favor the view that the $L 6 M A D$ protein coexpresses $L 6$ gene-forgene specificity together with autoactivity. However, our inability to demonstrate clear reaction of these plants to the Agrobacterium-delivered AvrL567- $a$ avirulence gene, possibly due to resistance to Agrobacterium, leaves some uncertainty about this allele's ability to recognize the avirulence gene product.

\section{The dwarf phenotype.}

One intriguing feature of flax plants transgenic for autoactive $L 6$ alleles is the dwarf phenotype. In its mild form, e.g., plants expressing $L 6-L 2 \mathrm{H} / \mathrm{Bgl}$ and $L 6 M A D$, plants have a reduced internode length but have an otherwise normal phenotype and are fully fertile. The dwarf phenotype is not counteracted by application of the gibberellin GA3 (J. Ellis, unpublished results). The phenotypes of homozygous L6MHV flax and Arabidopsis lines homozygous for ssi4 (Shirano et al. 2002), adrl (Grant et al. 2003), bal (Stokes et al. 2002), ssil (Shah et al. 1999), and sncl (Zhang et al. 2003) are more extreme and, in Arabidopsis, include curled leaves. These differences probably result from an increased flux through the signal pathway downstream of the active $\mathrm{R}$ protein. The dwarf phenotype in several of the Arabidopsis mutants referred to above is associated with increased levels of salicylic acid (SA) and can be mimicked in transgenic plants expressing a bacterial gene for SA synthesis (Mauch et al. 2001). The dwarfing effects may be due to the "metabolic load" of constitutively expressing defense proteins such as PR1 (Heil and Baldwin 2002). The results of Tao and associates (2000) indicate another possibility. They showed that overexpression of Arabidopsis resistance gene RPS2 in transient assays gives rise to an "overdose" effect that is correlated with decreased generalized de novo protein synthesis. This is reminiscent of plant stress responses, such as anaerobic stress that both induces the transcription of anaerobic response genes and stops translation of "nonanaerobic" messenger RNA (Sachs et al 1980). A similar translational response may occur during defense activation. The dwarf phenotype in plants with autoactive $\mathrm{R}$ proteins may be derived from both metabolic load of defense protein expression and a general, partial reduction of normal nonstress protein synthesis through a translational control.

\section{Auto-active L6 confers resistance to rust strains virulent to $\mathbf{L 6}$.}

Most autoactive variants of other NBS-LRR $\mathrm{R}$ proteins cause increased resistance to normally virulent pathogens (Grant et al. 2002; Li et al. 2001; Shirano et al. 2002; Stokes et al. 2002; Zhang et al. 2003), but we find no reports of autoactive resistance being associated with HR induced by the pathogen at the infection site. Indeed, Li and associates (2001) report the contrary for the interaction of Arabidopsis and Peronospora parasitica in sncl mutants. However, there has been one report of resistance in Arabidopsis to an otherwise virulent $P$. parasitica, induced by the chemical $\mathrm{BTH}$, being associated with necrosis of host cells containing haustoria (Lawton et al. 1996). BTH induces defense gene expression and systemic acquired resistance. Resistance in autoactive flax plants to $L 6$-virulent rust strains was associated with clear HR. Perhaps even in the absence of effective resistance genes, HR may be a "default" reaction of flax to infec- tion by flax rust. In compatible interactions "default" $\mathrm{HR}$ may be actively inhibited by pathogen-derived virulence factors that block host defenses at the infection site. Under this scenario, chemically induced or autoactive host defense responses may slow pathogen metabolism and growth sufficiently to counter the pathogen's ability to subvert basal resistance and prevent the default HR. Alternatively, rust infection may induce a localized increase in expression of the mutant L6 allele, the signal transduction components at the infection site that raises the level of these proteins over the threshold for cell death, or both. Autoactive resistance proteins may therefore have application in broad pathogen protection of transgenic crops if negative features such as the dwarf phenotype can be controlled.

\section{MATERIALS AND METHODS}

\section{Plant material and rust strains.}

Flax lines and flax rust strains have been described previously (Ellis et al 1999; Lawrence et al. 1981). Transformation procedures for the flax line Ward have been described (Anderson et al. 1997). Arabidopsis was transformed by the silwet-mediated floral dip method (Clough and Bent 1998).

\section{Agrobacterium-mediated transient expression assays.}

Binary vectors were transformed into Agrobacterium tumefaciens GV3101pMP90 by triparental mating. Strain C58C1 was used as a Ti plasmid-free strain to demonstrate the requirement of T-DNA transfer for the necrotic phenotype. The presence of the correct vectors in strains was checked by isolating DNA from the Agrobacterium, electroporating it into Escherichia coli, and isolating and sequencing DNA from the latter bacterium. Strains were prepared for transient assays by growth overnight $\left(28^{\circ} \mathrm{C}\right.$ and $\left.200 \mathrm{rpm}\right)$ in $50-\mathrm{ml}$ cultures of Luria broth containing gentamycin $(0.05 \mathrm{mg} / \mathrm{ml})$, tetracycline $(0.0035 \mathrm{mg} / \mathrm{ml})$, and $3 \mathrm{mM}$ acetosyringone (Aldrich, St. Quentin, France). Cultures were centrifuged in a SS34 rotor $\left(20^{\circ} \mathrm{C}\right.$ and $8,000 \mathrm{rpm}$ ) for $10 \mathrm{~min}$, and then were resuspended in Murashige-Skoog medium at an optical density at $600 \mathrm{~nm}$ of approximately 1.0. After incubation at room temperature for $1 \mathrm{~h}$, they were infiltrated by gentle pressure injection with a needleless syringe into the underside of tobacco leaves or cotyledons of flax seedlings. N. tabacum cv. Samsun NN plants were generally 4 to 6 weeks old, $N$. benthamiana plants were 6 to 8 weeks old, while the flax plants were 14-day-old seedlings. Usually, 2 to 3 weeks was necessary to observe a strong response in the tobacco species, while necrosis of the flax cotyledons was observable within 10 days.

\section{General nucleic acid techniques.}

All sequencing was performed on an Applied Biosystems (Foster City, CA, U.S.A.) 377 sequencer, and individual sequences were aligned and assembled by the use of the Sequencher program (Gene Codes Corporation, Ann Arbor, MI, U.S.A.). Oligonucleotide site-directed mutagenesis was conducted by the Gene-editor kit (Promega, Madison, WI, U.S.A.) or by the method of Kunkel and associates (1991). Primers used for mutagenesis in this study are as follows:

P1 GATGAGTTTAAAAAGCACGACCAACTTAGAGAT P2 GATGAGTTTAAAATGGCCGACCAACTTAGAGAT P3 GAGTTTAAAATGCACGTCCAACTTAGAGATATG P4 GAGTTTAAAATGCACAACCAACTTAGAGATATG P5 GAGTTTAAAATGCACCGCCAACTTAGAGATATG P6 GAGTTTAAAATGCACTCCCAACTTAGAGATATG P7 GAGTTTAAAATGCACCTCCAACTTAGAGATATG P8 TGTTTCTTGAATTAGTCAGATCTGAGATACCTCCATG P9 GTGGAATAGGCATGACGACCACTGC 
Construction of binary vectors carrying L6 MHD mutants.

The EcoR1-Sph1 fragment of the L6 gene (Lawrence et al. 1995) cloned in Bluescript (Stratagene, San Diego, CA, U.S.A.) was used for generating mutants of the L6 MHD motif. Primers $\mathrm{P} 1$ to $\mathrm{P} 7$ were used to create the mutations M539K, H540A, D541V, D541N, D541R, D541S, and D541L, respectively. Clones containing the mutations were confirmed by DNA sequencing, cleaved with EcoR 1 and $S p h 1$, and ligated into full-length $L 6$ genomic sequence and were similarly digested. The full-length clone extended from a SacI site 5' of the ATG codon to a $B g l I I$ site $3^{\prime}$ of the stop codon and was cloned as a SacI-BglII/BamH1 fusion clone in Bluescript. These mutated clones were then cleaved with $S a c$ I and SmaI and were ligated into either the binary vector pTNTRegL6 $\Delta \mathrm{EB}$ (endogenous L6 promoter) or pTNot35SL6 (35S CaMVpromoter). Both binary vectors were prepared for cloning by digestion, first with $B g l$ II, filling-in with dNTPs, and then by digestion with $S a c I$. Finally, for the transformation of flax and Arabidopsis, a unique PstI site in both vectors was used for the cloning of the 35S CaMV-driven spectinomycin and bialaphos (bar) resistance genes, respectively.

\section{L6 with mutant P-loop and with no LRR.}

The EcoRI-Sph 1 fragment of $L 6$ and the L6 D541V mutation were used to generate the constructs coding for the L6 protein devoid of the LRR region. In both clones, the codon for amino acid 604 was converted to an in-frame stop codon followed almost directly by a $B g l I I$ site, by the use of the primer P8. The fragments were sequenced and ligated into the $L 6$ genomic backbone, then were digested with $S a c I$ and $B g l I I$ and were ligated into the vector pTNTRegL6 $\triangle \mathrm{EB}$, cleaved with the same enzymes. Substitution of the critical lysine residue in the P-loop sequence with methionine (K271M) was created by mutagenesis of Bluescript clones (SacI-BglII/BamHI fusion) of the entire wild-type L6 and D541 mutant. These were sequenced, were cleaved with $S a c \mathrm{I}$ and $S m a \mathrm{I}$, and were ligated into pTNTRegL6 $\triangle \mathrm{EB}$, which was prepared for cloning by digestion with $B g l I I$, filling-in, and then, digestion with SacI.

\section{Construction of L6-L2 H/Bg and L6-L10 H/Bg alleles.}

The 3' 175-bp region of $L 6$ cloned into a binary vector (Ellis et al. 1999) was excised using a unique HindIII site in the coding region and a unique $B g l I I$ site downstream of the stop codon and was replaced with the corresponding fragments from $L 2$ and $L 10$.

\section{Construction of binary vectors coding for ethanol-inducible $L 6, L 6 M H V$, and Fis $1 L 6 M H V$.}

$S a c \mathrm{I}-B g l \mathrm{II} / \mathrm{BamHI}$ fusion clones of the entire genomic wildtype and that containing the D541V mutant L6 genes were digested with $S a c I$ and $S m a I$, were filled-in with the Klenow fragment and dNTPs, and were ligated to the vector pACN, which had been digested with SalI and filled-in in a similar manner. Each of the resulting clones was partially digested with HindIII, and the fragments containing the L6 sequences and flanking alc promoters and nos terminators were ligated into the binary vector pbinSRNACatN, which was prepared for cloning by digestion with HindIII. Plasmids pACN and pbinSRNACatN (Caddick et al. 1998) were obtained from and used under agreement with Syngenta Jealott's Hill (Berkshire, U.K.). The Fis $1 L 6 M H V$ vector was constructed as described previously (Ayliffe et al. 2002).

\section{RNA extraction and Northern analysis.}

Total RNA was extracted by a guanidinium isothiocyanate method (Chomczynski and Sacchi 1987). Samples were elec- trophoresed on a $1 \%$ formaldehyde gel and were transferred to Hybond-N (Amersham, Tokyo) by standard procedures (Sambrook and Russell 2001).

\section{PR1 expression in flax.}

A flax PR1 homologue probe for gene expression analysis was amplified by PCR from genomic DNA of the flax line Ward. The redundant primers, containing inosine, were based on conserved regions in PR1 proteins from several plant species and the sequences were $\operatorname{GCICA}(\mathrm{A} / \mathrm{G})(\mathrm{A} / \mathrm{G}) \mathrm{A}(\mathrm{T} / \mathrm{C})$ (T/A) $(\mathrm{C} / \mathrm{G}) \mathrm{IC}(\mathrm{A} / \mathrm{C}) \mathrm{ICA}(\mathrm{A} / \mathrm{G}) \mathrm{GA}(\mathrm{T} / \mathrm{C}) \mathrm{TA}$ and CCAIACIA $(\mathrm{C} / \mathrm{T})$ $(\mathrm{C} / \mathrm{T})$ TGIGT $(\mathrm{A} / \mathrm{G}) \mathrm{TA}(\mathrm{A} / \mathrm{G}) \mathrm{TG}$. PCR conditions were $94^{\circ} \mathrm{C}$ for $2 \mathrm{~min}$ and then 40 cycles of $94^{\circ} \mathrm{C}(20 \mathrm{~s}), 46^{\circ} \mathrm{C}(20 \mathrm{~s}), 72^{\circ}$ $(55 \mathrm{~s})$. The reaction products were cloned into the vector pGEMT (Promega), and clones were confirmed by sequencing. Two approximately 320-bp products were isolated, and both encoded related PR1 homologues, as determined by Blast P analysis after removing the amino acid sequences encoded by the primer sequences. Clone 13 (NCBI accession number AY559144) was used in RNA gel blot analysis. PR1 expression in flax was induced using BTH (1,2,3,-benzothiadiazole7-carbothioic-acid- $S$-methyl ester) as Bion $500 \mathrm{WG}$, supplied by Novartis Crop Protection Australasia Pty Ltd. (Pendle Hill, Australia).

\section{Chitinase assay.}

The chitinase assay is described by Wirth and Wolf (1990). Leaf tissue (approximately $0.2 \mathrm{~g}$ of fresh weight), comprising the young, developing leaves at the tip of the plant and eight to ten fully expanded leaves below the tip, was collected from flax plants. These leaf samples were ground in Eppendorf tubes with buffer ( $200 \mu \mathrm{l}, 0.05 \mathrm{M}$ sodium acetate, $\mathrm{pH} 5.0)$ and a small quantity (approximately $20 \mathrm{mg}$ ) of a 1:1 mixture of acid-washed sand and insoluble polyvinyl pyrrolidone. More buffer $(800 \mu \mathrm{l})$ was added, and the mixture was centrifuged and kept on ice until required. Chitinase activity was determined using carboxymethylchitin-remazol brilliant violet solution $\left(2 \mathrm{mg} \mathrm{ml}^{-1}\right)$ (Loewe Biochemica, Munich) as substrate. After incubation $\left(30 \mathrm{~min}\right.$ at $\left.37^{\circ} \mathrm{C}\right)$, undigested substrate was precipitated with $\mathrm{HCl}$ and was removed by centrifugation. An estimate of the chitinase activity was made by measuring the difference between the absorbance at $540 \mathrm{~nm}\left(\mathrm{~A}_{540}\right)$ values of an aliquot of supernatant from a digested and an undigested reaction (when $\mathrm{HCl}$ was added immediately). Protein concentrations in the diluted extracts were determined, using a bicinchoninic acid kit (Pierce, Rockford, IL, U.S.A.) according to the manufacturer's directions. Chitinase activities were expressed as $\Delta \mathrm{A}_{540}$ obtained per milligram of soluble protein.

\section{Ethanol induction of alc $A$-driven constructs in transgenic Arabidopsis and flax.}

Transgenic plants containing the alcA/alcR gene expression systems were grown in soil under greenhouse conditions of $22^{\circ} \mathrm{C}$ day and $18^{\circ} \mathrm{C}$ night. A 12 -h-day period was used for Arabidopsis. Approximately 4- to 5-week-old plants were sprayed with a $2 \%$ ethanol spray (Roslan et al. 2001), were covered with plastic for $24 \mathrm{~h}$, and then, their response to the treatment was observed. Ethanol induction was also done with transgenic plants growing in sterile tissue culture. PRI and L6 gene expression in these plants was detected, using the coding regions of the genes amplified from genomic DNA of Arabidopsis and the cloned coding region of $L 6$, respectively.

\section{Autofluorescence assay.}

Five days after treatment (rust and mock infections), flax leaves were removed from the plant, were boiled 2 to $3 \mathrm{~min}$ in absolute ethanol with a few glass beads. The leaves were then 
placed in a saturated aqueous solution of chloral hydrate (Sigma, St. Louis) at room temperature. Cleared leaves were viewed under a microscope with a UV light source.

\section{ACKNOWLEDGMENTS}

V. Ryle, X. Zhu, and P. Atkinson provided excellent technical assistance for this research. This research was partly funded by the Grains Research and Development Corporation (Canberra, Australia).

\section{LITERATURE CITED}

Altschul, S. F., Gish, W., Miller, W., Myers, E. W., and Lipman, D. J. 1990. Basic local alignment search tool. J. Mol. Biol. 215:403-410.

Anderson, P. A., Lawrence, G. J., Morrish, B. C., Ayliffe, M. A., Finnegan, J. E., and Ellis, J. G. 1997. Inactivation of the flax rust-resistance gene $\mathrm{M}$ associated with loss of a repeated unit within the leucine-rich repeat coding region. Plant Cell 9:641-651.

Aravind, L., Dixit, V. M., and Koonin, E. V. 1999. The domains of death: evolution of the apoptosis machinery. Trends Biochem. Sci. 24:47-53.

Axtell, M. J., and Staskawicz, B. J. 2003. Initiation of RPS2-specified disease resistance in Arabidopsis coupled to the AcrRpt2-directed elimination of RIN4. Cell 112:369-77.

Ayliffe, M. A., Roberts, J. K., Mitchell, H. J., Zhang, R., Lawrence, G. J. Ellis, J. G., and Pryor, T. J. 2002. A plant gene up-regulated at rust infection sites. Plant Physiol. 129:169-180.

Ballesteros, J. A., Jensen, A. D., Liapakis, G., Rasmussen, L., Gether, U., and Javitch, J. A. 2001. Activation of the $\beta_{2}$-adrenergic receptor involves disruption of an ionic lock between the cytoplasmic ends of transmembrane segments 3 and 6. J. Biol. Chem. 276:29171-29177.

Bendahmane, A., Farnham, G., Moffett, P., and Baulcombe, D. C. 2002. Constitutive gain-of-function mutants in a nucleotide binding siteleucine rich repeat protein encoded at the Rx locus of potato. Plant $\mathrm{J}$. 32:195-204.

Bertin, J., Nir, W.-J., Fischer, C. M., Tayber, O. V., Errada, P. R., Grant, J. R., Keilty, J. J., Gosselin, M. L., Robison, K. E., Wong, G. H., Glucksmann, M. A., and DiStefano, P. S. 1999. Human CARD4 protein is a novel CED-4/Apaf-1 cell death family member that activates NFkappaB. J. Biol. Chem. 274:12955-12958.

Bowling, S. A., Clarke, J. D., Liu, Y., Klessig, D. F., and Dong, X. 1997. The cpr5 mutant of Arabidopsis expresses both NPR1-development and NPR1-independent resistance. Plant Cell 9:1573-1584.

Caddick, M. X., Greenland, A. J., Jepson, I., Krause, K.-P., Qu, N., Riddell, K. V., Salter, M. G., Schuch, W., Sonnewald, U., and Tomsett, A. B. 1998. An ethanol inducible gene switch for plants: Manipulation of carbon metabolism. Nature Biotech 16:177-180.

Chinnaiyan, A. M., Chaudhary, D., O'Rourke, K., Koonin, E. V., and Dixit, V. M. 1997. Role of CED-\$ in the activation of CED-3. Nature 388:728-729.

Chomczynski, P., and Sacchi, N. 1987. Single-step method of RNA isolation by acid guanidinium thiocyanate-phenol-chloroform extraction. Anal. Biochem. 162:56-159.

Clough, S. J., and Bent, A. F. 1998. Floral dip: A simplified method for Agrobacterium-mediated transformation of Arabidopsis thaliana. Plant J. 16:735-43.

Collins, N. C., Webb, C. A., Seah, S., Ellis, J. G., Hulbert, S. H., and Pryor, A. 1998. The isolation and mapping of disease resistance gene analogs in maize. Mol. Plant-Microbe Interact. 11:968-978.

Dangl, J. L., and Jones, J. D. 2001. Plant pathogens and integrated defence responses to infection. Nature 411:826-33.

Deslandes, L., Olivier, J., Peeterson, Feng, D. X., Khounlotham, M., Boucher, C., Somssich, I., Genin, S., and Marco, Y. 2003. Physical interaction between RRS1-R, a protein conferring resistance to bacterial wilt, and PopP2, a type III effector targeted to the plant nucleus. Proc. Natl. Acad. Sci. U.S.A. 100:8024-8029.

Dodds, P. N., Lawrence, G. J., Catanzariti, A. M., Ayliffe, M. A., and Ellis, J. G. 2004. The Melampsora lini AvrL567 avirulence genes are expressed in haustoria and their products are recognized inside plant cells. Plant Cell 16:755-68.

Dolferus, R., Marbaix, G., Jacobs, M. 1985. Alcohol dehydrogenase in Arabidopsis: Analysis of the induction phenomenon in plantlets and tissue cultures. Mol. Gen. Genet. 199:256-264.

Ellingboe, A. H. 1981. Changing concepts in host-pathogen genetics. Ann. Rev. Phytopathol. 19:125-143.

Ellis, J. G., Lawrence, G. J., Luck, J. E., and Dodds, P. N. 1999. Identification of regions in alleles of the flax rust resistance gene $L$ that determines differences in gene-for-gene specificity. Plant Cell 11:495-506.

Falk, A., Feys, B. J., Frost, L. N. Jones, J. D., Daniels, M. J., and Parker, J. E.
1999. EDS1, an essential component of $R$ gene-mediated disease resistance in Arabidopsis has homology to eukaryotic lipases. Proc. Natl. Acad. Sci. U.S.A. 96:3292-3297.

Frost, D., Way, H., Howles, P., Luck, J., Manners, J. Hardham, A., Finnegan, J., and Ellis, J. 2004. Tobacco transgenic for the flax rust resistance gene $L$ expresses allele-specific activation of defense responses. Mol. Plant-Microbe Interact. 17:224-232.

Grant, J. J., Chini, A., Basu, D., and Loake, G. J., 2003. Targeted activation tagging of the Arabidopsis NBS-LRR gene, ADR1, conveys resistance to virulent pathogens. Mol. Plant-Microbe Interact. 16:669-680.

Grant, M. R., Godiard, L., Straube, E., Ashfield, T., Lewald, J., Sattler, A., Innes, R. W., and Dangl, J. L. 1995. Structure of the Arabidopsis RPMI gene enabling dual specificity disease resistance. Science 269:843-846.

Heil, M. and Baldwin, I. T. 2002. Fitness costs of induced resistance: Emerging experimental support for a slippery concept. Trends Plant Sci. 7:61-67.

Hwang, C., and Williamson, V. M. 2003. Leucine-rich repeat-mediated intramolecular interactions in nematode recognition and cell death signaling by the tomato resistance protein Mi. Plant J. 34:585-593.

Inohara, N., Koseki, T., del Peso, L., Hu, Y., Yee, C., Chen, S., Carrio, R., Merino, J., Liu, D., Ni, J., and Nunez, G. 1999. Nod1, and Apaf-1-like activator of caspase-9 and nuclear factor-kappaB. J. Biol. Chem. 274:14560-14567.

Jia, Y., McAdams, S. A., Bryan, G. T., Hershey, H. P., and Valent, B. 2000. Direct interaction of resistance gene and avirulence gene products confers rice blast resistance. EMBO (Eur. Mol. Biol. Organ.) J. 19:4004-4014.

Junker, B. H., Chu, C., Sonnewald, U., Willmitzer, L., and Fernie, A. R. 2003. In plants the alc gene expression system responds more rapidly following induction with acetaldehyde than with ethanol. FEBS (Fed. Eur. Biochem. Soc.) Lett. 535:136-140

Kunkel, T. A., Bebenek, K., and McClary, J. 1991. Efficient site-directed mutagenesis using uracil-containing DNA. Method Enzymol. 204:125139.

Lawton, K. A., Friedrich, L., Hunt, M., Weymann, K., Delaney, T., Kessmann, H., Staub, T., and Ryals, J. 1996. Benzothiadiazole induces disease resistance in Arabidopsis by activation of the systemic acquired resistance signal transduction pathway. Plant J. 10:71-82.

Lawrence, G. J., Mayo, G. M. E, and Shepard, K. W. 1981. Interactions between genes controlling pathogenicity in the flax rust fungus. Phytopathology 71:12-19.

Lawrence, G. J., Finnegan, J. E., Ayliffe, M. A., and Ellis, J. G. 1995. The L6 gene for flax rust resistance is related to the Arabidopsis bacterial resistance gene RPS2 and the tobacco viral resistance gene $N$. Plant Cell 7:1195-1206

Li, X., Clarke, J. D., Zhang, Y. and Dong, X. 2001. Activation of an EDS1mediated $R$-gene pathway in the sncl mutant leads to constitutive, NPR1-independent pathogen resistance. Mol Plant-Microbe Interact. 14:1131-1139

Mackey, D., Belkhadir, Y., Alonso, J .M., Ecker, J. R., and Dangl, J. L. 2003. Arabidopsis RIN4 is a target of the type III virulence effector AvrRpt2 and modulates RPS2-mediated resistance. Mol. Cell 11:284-286.

Mauch, F., Mauch-Mani, B., Baille, V., Kull, B., Haas, D., and Reimmann, C. 2001. Manipulation of salicylate content in Arabidopsis thaliana by the expression of an engineered bacterial salicylate synthase. Plant $\mathbf{J}$. 25:67-77.

Mindrinos, M., Katagiri, F., Yu, G. L., and Ausbel, F. M. 1994. The A. thaliana disease resistance gene RPS2 encodes a protein containing a nucleotide-binding site and leucine-rich repeats. Cell 78:1089-1099.

Moffett, P., Farnham, G., Peart, J., and Baulcombe, D. C. 2002. Interaction between domains of a plant NBS-LRR protein in disease resistancerelated cell death. The EMBO (Eur. Mol. Biol. Organ.) J. 21:45114519.

Ogura, Y., Inohara, N., Benito, A., Chen, F. F., Yamaoka, S., Nuñez, G. 2001. Nod2, a Nod1/Apaf-1 family member is restricted to monocytes and activates NF-kappaB. J. Biol. Chem. 276:4812-4818.

Oldroyd, G. E.D., and Staskawicz, B. J. 1998. Genetically engineered broad-spectrum disease resistance in tomato. Proc. Natl. Acad. Sci. U.S.A. 95:10300-10305.

Rodriguez A., Oliver H., Zou H., Chen P., Wang X., and Abrams, J. M. 1999 Dark is a Drosophila homologue of Apaf-1/CED-4 and functions in an evolutionarily conserved death pathway. Nat. Cell Biol. 1:272-279.

Roslan, H. A., Salter, M. G., Wood, C. D., White, M. R., Croft, K. P., Robson, F., Coupland, G., Doonan, J., Laufs, P., Tomsett, A. B., and Caddick, M. X. 2001. Characterisation of the ethanol-inducible alc gene-expression system in Arabidopsis thaliana. Plant J. 28:225-35.

Sachs, M. M., Freeling, M., and Okimoto, R. 1980 The anaerobic proteins of maize. Cell 20:761-767.

Sambrook, J., and Russell, D. W. 2001. Molecular Cloning. A Laboratory Manual. 3rd ed. Cold Spring Harbor Laboratory Press, Cold Spring Harbor, NY, U.S.A. 
Scofield, S. R., Tobias, C. M., Rathjen, J. P., Chang, J. H., Lavelle, D. T., Michelmore, R. M., and Staskawicz, B. J. 1996. Molecular basis of gene-for-gene specificity in bacterial speck disease of tomato. Science 274:2063-2065

Shah, J., Kachroo, P., and Klessig, D. F., 1999. The Arabidopsis ssil mutation restores pathogenesis-related gene expression in $n p r l$ plants and renders defensin gene expression salicylic acid dependent. Plant Cell 11:191-206

Shao, F., Golstein, C., Ade, J., Stoutemyer, M., Dixon, J. E., and Innes, R. W. 2003. Cleavage of Arabidopsis PBS1 by a bacterial type III effector. Science 301:1230-1233.

Shirano, Y., Kachroo, P., Shah. J., and Klessig, D. F. 2002. A gain-of-function mutation in an Arabidopsis toll interleukin1 receptor-nucleotide binding site-leucine-rich repeat type $R$ gene triggers defense responses and results in enhanced disease resistance. Plant Cell 14:3149-162.

Stokes, T. L., and Richards E. J. 2002. Induced instability of two Arabidopsis constitutive pathogen-response alleles. Proc. Natl. Acad. Sci. U.S.A. 99:7792-7796.

Stokes, T. L., Kunkel, B. N., and Richards E. J. 2002. Epigenetic variation in Arabidopsis disease resistance. Genes Dev. 16:171-182.

Sun, Q., Collins, N. C., Ayliffe, M., Smith, S. M., Drake, J., Pryor, T. and Hulbert, S. H. 2001. Recombination between paralogues at the rp1 rust resistance locus in maize. Genetics 158:423-438.

Tang, X., Frederick, R. D., Zhou, J., Halterman, D. A., Jia, Y., and Martin, G. B. 1996. Initiation of plant disease resistance by physical interaction of AvrPto and Pto kinase. Science 274:2060-2063.

Tao, Y., Yuan, F., Leister, R. T., Ausubel, F. M., and Katagiri, F., 2000.
Mutational analysis of the Arabidopsis nucleotide binding site-leucinerich repeat resistance gene RPS2. Plant Cell 12:2541-2554.

Tameling, W. I., Elzinga, S. D., Darmin, P. S., Vossen, J. H., Takken, F. L., Haring, M. A., and Cornelissen, B. J. 2002. The tomato $R$ gene products I-2 and MI-1 are functional ATP binding proteins with ATPase activity. Plant Cell 14:2929-2939

Traut, T. W. 1994. The functions and consensus motifs of nine types of peptide segments that form different types of nucleotide binding sites. Eur. J. Biochem. 222:9-19.

Van der Biezen, E. A., and Jones, J. D. 1998. The NB-ARC domain: A novel signaling motif shared by plant resistance gene products and regulators of cell death in animals. Curr. Biol. 8:226-7.

Wirth, S. J., and Wolf, G. A. 1990. Dye-labeled substrates for the assay and detection of chitinase and lysozyme activity. J. Microbiol. Method 12:197-205.

Yang, S., and Hua, J. 2004. A haplotype-specific resistance gene regulated by BONZAI1 mediates temperate-dependent growth control in Arabidopsis. Plant Cell 16:1060-1071.

Zhang, Y., Goritschnig, S., Dong, X., and Li, X. 2003. A gain-of-function mutation in a plant disease resistance gene leads to constitutive activation of downstream signal transduction pathways in suppressor of npr11, constitutive 1. Plant Cell 15:2636-2646.

\section{AUTHOR-RECOMMENDED INTERNET RESOURCE}

The National Center for Biotechnology Information Blast 2 sequences website: www.ncbi.nlm.nih.gov/blast/bl2seq/bl2.html 